\title{
The new Zero-P implant can effectively reduce the risk of postoperative dysphagia and complications compared with the traditional anterior cage and plate: a systematic review and meta-analysis
}

Mengchen Yin ${ }^{1,2+}$, Junming Ma ${ }^{1 \dagger}$, Quan Huang ${ }^{2 \dagger}$, Ye Xia', Qixing Shen ${ }^{1}$, Chenglong Zhao ${ }^{2}$, Jun Tao ${ }^{2}$, Ni Chen ${ }^{1}$, Zhingxing $\mathrm{Yu}^{1}$, Jie $\mathrm{Ye}^{1}$, Wen $\mathrm{Mo}^{1 *}$ and Jianru Xiao ${ }^{2^{*}}$

\begin{abstract}
Background: The low-profile angle-stable spacer Zero-P is a new kind of cervical fusion system that is claimed to limit the potential drawbacks and complications. The purpose of this meta-analysis was to compare the clinical and radiological results of the new Zero-P implant with those of the traditional anterior cage and plate in the treatment of symptomatic cervical spondylosis, and provides clinicians with evidence on which to base their clinical decision making.

Methods: The following electronic databases were searched: PMedline, PubMed, EMBASE, the Cochrane Central Register of Controlled Trials, Evidence Based Medicine Reviews, VIP, and CNKI. Conference posters and abstracts were also electronically searched. The efficacy was evaluated in intraoperative time, intraoperative blood loss, fusion rate and dysphagia.

Results: For intraoperative time and intraoperative blood loss, the meta-analysis revealed that the Zero-P surgical technique is not superior to the cage and plate technique. For fusion rate, the two techniques both had good bone fusion, however, this difference is not statistically significant. For decrease of JOA and dysphagia, the pooled data showed that the Zero-P surgical technique is superior to the cage and plate technique.
\end{abstract}

Conclusions: Zero-P interbody fusion can attain good clinical efficacy and a satisfactory fusion rate in the treatment of symptomatic cervical spondylosis. It also can effectively reduce the risk of postoperative dysphagia and its complications. However, owing to the lack of long-term follow-up, its long-term efficacy remains unknown.

Keyword: Systematic review, Cervical spine, Cervical spondylosis, Cage, Zero-P plate

\footnotetext{
*Correspondence: mw2218@126.com; jianruxiao83@163.com

${ }^{\dagger}$ Equal contributors

'Department of Orthopaedics, LongHua hospital, Shanghai university of

Traditional Chinese Medicine, Shanghai, People's Republic of China

2Department of Bone Tumor Surgery, Changzheng Hospital, Second Military

Medical University, Shanghai, People's Republic of China
} 


\section{Background}

Cervical spondylosis is a frequent cause of radicular arm pain, and is a leading cause of spinal cord dysfunction in adults. Surgical treatment is indicated when conservative therapy fails or when the symptoms worsen [1, 2]. In 1958, Cloward, Smith, and Robinson first reported that anterior cervical operation is a safe and effective method for the treatment of degenerative cervical spondylosis. Anterior cervical discectomy and fusion (ACDF) is still performed in most cases and is the golden standard for the treatment of cervical spondylosis, regardless of whether a single segment or multiple segments are involved [3-5]. At present, cages are widely used for cervical fusion clinically. These techniques have their own benefits as well as potential drawbacks and adverse effects. The most often mentioned shortcomings of these techniques are sacrifices of the original activity of the segment and changes in stress distribution of the adjacent segment [6, 7]. These will accelerate disc degeneration and cause many complications, such as postoperative dysphagia for the anterior plate constructs [8-10]. Many studies have reported that an anterior plate with a lower, smoother profile may reduce the incidence of dysphagia after ACDF [11, 12].

Low-profile angle-stable spacer Zero-P, which was approved by the United States Food and Drug Administration in 2008, is a new kind of cervical fusion system that has been declared to limit the potential risk of these drawbacks and complications. The design of Zero-P is based on the polyetheretherketone (PEEK) intervertebral fusion Syncage $-C$, where the small titanium plate is integrally inserted into the intervertebral disc, which is then secured to the upper and lower vertebral body by the insertion of screws. The advantages of using intervertebral fusion cage and plate can also be attained via Zero-P. In particular, it can increase the immediate stability of treated segment even in the absence of an anterior implant, and decrease the incidence of postoperative dysphagia and adjacent segments degeneration. There is still no comprehensive review regarding the comparative analysis on outcomes between these two cervical spine procedures. Consequently, this article is the first metaanalysis based on all literatures to compare clinical and radiological results of the new Zero-P implant with those using traditional anterior cage and plate in the treatment of symptomatic cervical spondylosis, and to provide clinicians with an evidence base for their clinical decision making.

\section{Methods}

\section{Search strategy}

The research group followed the recommendations of Preferred Reporting Items for Systematic Reviews and Meta-Analyses (PRISMA) for this meta-analysis [13].
The following electronic databases were searched from their inception dates through August 2013: Medline, PubMed, EMBASE, the Cochrane Central Register of Controlled Trials, Evidence Based Medicine Reviews, VIP, and CNKI. The study used Boolean logic with search terms including "Zero-P", "cervical spondylosis," and "cervical fusion." The references for all located articles, including other systematic reviews, were searched manually for additional relevant articles.

\section{Inclusion criteria \\ Types of studies}

The research group included all studies comparing the new Zero-P implant with the traditional anterior cage and plate in the treatment of symptomatic cervical spondylosis. Studies that provided no information about complications and had no specific data on the clinical effect were excluded. All basic research reports (biomechanics and basic science studies) were also excluded.

\section{Types of participants}

The research group excluded trials in which a specific cervical disease could be identified, such as fracture, trauma, developmental cervical stenosis, ossification of the posterior longitudinal ligament, and a previous cervical spinal surgery.

\section{Types of outcomes Surgical details}

Intraoperative time and intraoperative blood loss are important objective bases for the evaluation of operation situation. Therefore, they can have objective through comparison the evaluation of operation trauma.

\section{Radiographic outcomes}

The procedure of using a traditional cage combined with a plate has been recognized to have a good bony fusion rate. This review aimed to determine the outcome of the new Zero-P device through the comparison of the fusion rates of the operated segments at the last follow-up.

\section{Clinical outcome \\ Japanese Orthopaedic Association (JOA) score}

The review was more pertinent than other studies with regards to comparing the two operative procedures for treating cervical degenerative disease. Therefore, research group set the decrease of JOA score as the primary outcome, in the evaluation of clinical outcome, which was assessed at the last follow-up after the intervention.

\section{Dysphagia and its complications}

Dysphagia and its related complications are common after anterior cervical fusion surgery, and its incidence 
varies in the literature. Therefore, this review also focuses on evaluating postoperative dysphagia and its complications as adverse events in order to compare the efficacy of the two procedures.

\section{Data extraction and validity assessment}

All the study characteristics and outcome data were extracted from all the included studies independently. The research group extracted the details of trials, and if certain elements were missing, respective study authors were contacted to obtain the relevant missing data. Any differences in opinion about eligibility were resolved by consensus.

Assessment of methodological quality and heterogeneity Two independent reviewers assessed the methodological quality by using the Newcastle-Ottawa Scale, while modifying it to match the needs of this study [14, 15]. The quality was evaluated by examining three items: selection, comparability, and exposure, with higher scores representing studies of higher quality. The quality of each study was graded as either level $1(0-5)$ or level 2 (6-9) [16]. This review also assessed the clinical heterogeneity to evaluate whether the trials were similar enough to pool data.

\section{Assessment of risk bias}

The risks of bias of all included trials were also independently assessed by the other two reviewers according to the criteria of the Cochrane Handbook for Systematic Reviews.

\section{Data analysis}

In the review, for categorical data, dysphagia and its complications were dichotomized into two categories. The effect size for a reported decrease of JOA score was defined as a pooled estimate of the weighted mean difference (WMD) in the change.

The heterogeneity of all the studies was determined by $\mathrm{I}^{2}$ statistics. If the $\mathrm{I}^{2}$ value was $>50 \%$, the study marked it as a considerable level of heterogeneity; otherwise, it was considered to be of good homogeneity. The research group also assessed clinical heterogeneity. Statistically and clinically homogeneous studies were pooled using a fixed-effects model; otherwise, a random-effects model was used when the heterogeneity was significant.

\section{Results}

\section{Study description and risk bias}

Finally, five studies were incorporated into the systematic review, with a total enrolment of 472 patients and available follow-up data [17-21]. Figure 1 shows the selection process. Four clinical trials are retrospective studies. Only one trial is a prospective study. Table 1 summarizes the demographic data from these studies, and Table 2 presents the assessment of methodological quality. None studies demonstrated randomization and sufficient allocation concealment. None described the blinding of outcome assessment, participants and personnel. All studies retained complete outcome data and avoided selective reporting. As a result, the overall quality of the included studies demonstrated a high risk of bias.

\section{Surgical details \\ Intraoperative time}

3 studies were selected for the criterion on intraoperative time (minutes). The pooled data showed that patients submitted to the Zero-P technique did not have a significantly shorter intraoperative time than those who underwent the cage and plate technique of cervical fusion, in the randomeffects model (3 trials, $n=306$, pooled WMD $=-10.22$, $95 \% \mathrm{CI}=-21.67$ to $1.24, P=0.08$ ) (Fig. 2).

\section{Intraoperative blood loss}

For the outcome measure on Intraoperative blood loss $(\mathrm{ml})$, three studies were selected. The meta-analysis revealed that the Zero-P surgical technique is not superior to the cage and plate technique for this outcome measure in the fixed-effects model ( 3 trials, $n=$ 306 , pooled $\mathrm{WMD}=-10.78,95 \% \mathrm{CI}=-24.20$ to 2.65 , $P=0.12$ ) (Fig. 3).

\section{Radiographic outcome \\ Fusion rate}

The results of the three studies showed that all surgical levels in both groups had good bone fusion. In one study, all patients who were submitted to the interbody technique presented better results for this outcome. All surgical levels showed good fusion after the operation in three trials. One trial reported that $97.1 \%$ in the Zero-P group and $100 \%$ in the cage + plate group had good bone fusion; however, this difference is not statistically significant.

\section{Clinical outcome and complications \\ Decrease of JOA score}

Three studies used the decrease in JOA score to evaluate the clinical outcome. The pooled data showed that in terms of the decrease in JOA score, Zero-P was not more effective than ACDF in the fixed-effects model (3 trials, $n=205$, pooled $\mathrm{WMD}=0.22,95 \% \mathrm{CI}=-0.78$ to $0.35, P=0.75$ ) (Fig. 4).

\section{Dysphagia (early postoperative period)}

All five studies reported dysphagia in the early postoperative follow-up for both the Zero-P and the cage + plate group. The pooled data showed that the Zero-P group 


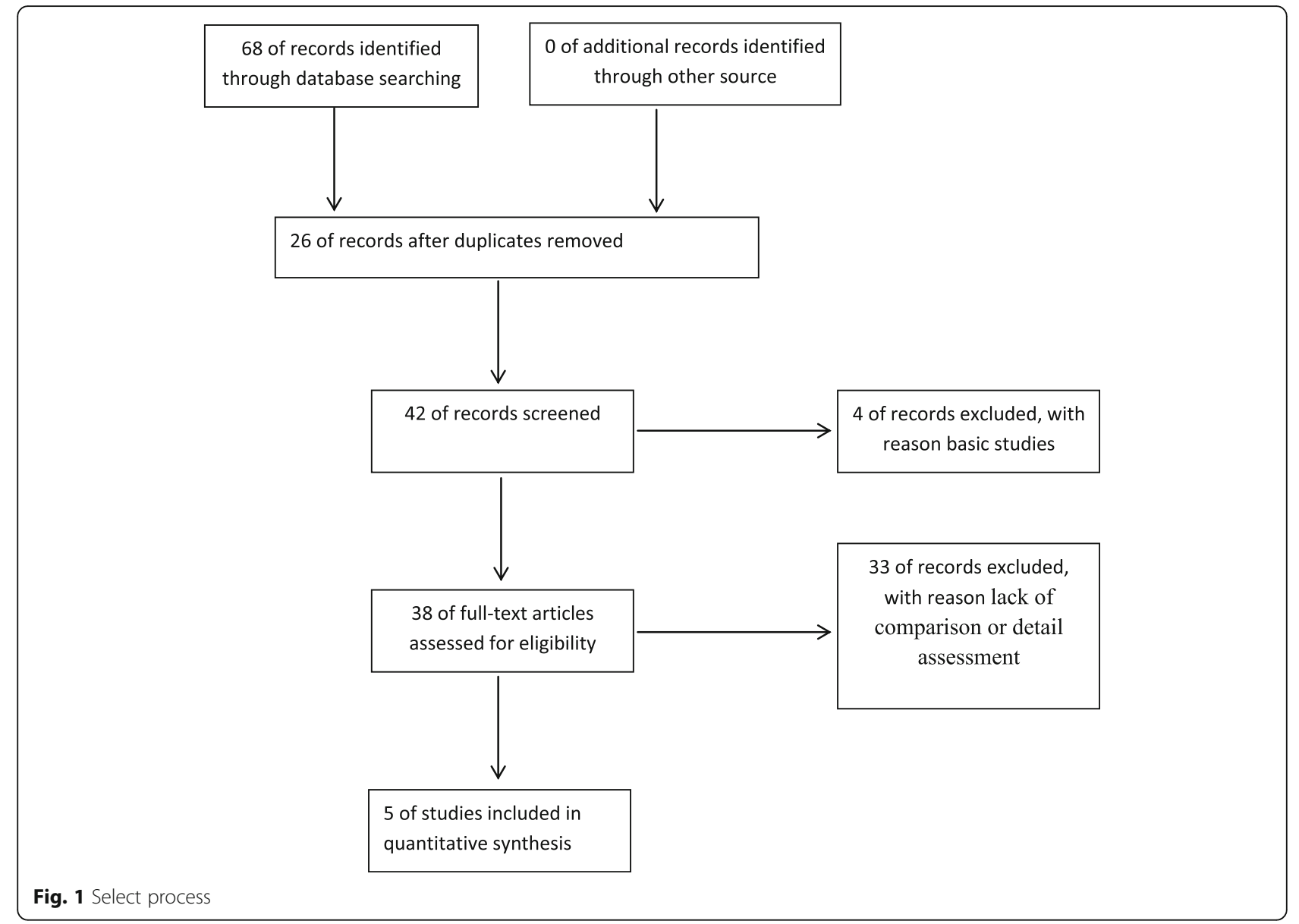

had a lower incidence of dysphagia and complication compared with the ACDF group in the fixed-effects model ( 5 trials, $n=472$, pooled $\mathrm{RR}=0.76,95 \% \mathrm{CI}=0.58$ to $0.98, \mathrm{Z}=2.10, P=0.04$ ) (Fig. 5).

\section{Dysphagia (at last follow-up)}

All five studies also described difficulty in swallowing at the last follow-up for both the Zero-P and the cage + plate group. The difference between the two groups was statistically significant. The incidence of dysphagia was lower at the last follow-up in the Zero-P group than in the ACDF group in the fixed-effects model ( 5 trials, $n=472$, pooled
$\mathrm{RR}=0.19,95 \% \mathrm{CI}=0.06$ to $0.58, Z=2.92, P=0.004$ ) (Fig. 6).

\section{Discussion}

Anterior cervical decompression by discectomy followed by fusion is a widely accepted and safe surgical procedure for the treatment of degenerative cervical spine disease [22]. The primary aim of this technique is to decompress the spinal cord and the affected nerve roots while restoring cervical alignment.

Seventy to $80 \%$ of cases that were treated with complete discectomy alone led to spontaneous bony fusion; therefore, anterior cervical discectomy with or without interbody

Table 1 Demographic data

\begin{tabular}{|c|c|c|c|c|c|c|c|c|}
\hline & \multirow[t]{2}{*}{ Design } & \multicolumn{2}{|c|}{ Number } & \multicolumn{2}{|l|}{ Age } & \multicolumn{2}{|c|}{ Segment } & \multirow[t]{2}{*}{ Follow-up (year) } \\
\hline & & $\bar{Z}$ & $c+p$ & 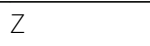 & $c+p$ & Z & $c+p$ & \\
\hline Wang 2013 & $\mathrm{R}$ & 22 & 24 & $50.86 \pm 8.79$ & $53.33 \pm 8.98$ & 44 & 48 & 2 \\
\hline Petr 2013 & $P$ & 44 & 33 & $50.2 \pm 10.3$ & $51.8 \pm 10.9$ & 55 & 41 & 2 \\
\hline Miao 2013 & $\mathrm{R}$ & 39 & 50 & $50.3 \pm 25.9$ & $52.6 \pm 23.7$ & 71 & 97 & 2 \\
\hline Hofstetter 2013 & $R$ & 35 & 35 & $56.8 \pm 1.6$ & $51.5 \pm 2.0$ & 53 & 54 & 2 \\
\hline QI 2013 & $R$ & 83 & 107 & $43.6 \pm 26.7$ & $44.9 \pm 27.4$ & 175 & 225 & 1.5 \\
\hline
\end{tabular}

Abbreviations: $N$ number of patient, $Z$ Zero-P group, $c+p$ cage and plate group, $P$ Prospective Study, $R$ Retrospective Study 
Table 2 Assessment of methodological quality

\begin{tabular}{lllllllll}
\hline & \multicolumn{1}{l}{ selection } & \multicolumn{2}{l}{ comparability } & exposure & scores \\
\hline & 1 & 2 & 3 & 4 & 5 & 6 & 7 & \\
Wang 2013 & & $*$ & $*$ & $*$ & $*$ & & $*$ & $* * * * *$ \\
Petr 2013 & $*$ & $*$ & $*$ & $* *$ & $* *$ & $*$ & $*$ & $* * * * * * * *$ \\
Miao 2013 & & $*$ & $*$ & $*$ & $*$ & $*$ & $*$ & $* * * * * *$ \\
Hofstetter 2013 & $*$ & $*$ & $*$ & $* *$ & $*$ & $*$ & $*$ & $* * * * * * *$ \\
Ql 2013 & $*$ & $*$ & $*$ & $*$ & $*$ & $*$ & $*$ & $* * * * * *$ \\
\hline
\end{tabular}

fusion is a widely accepted technique [23]. However, this technique is criticized because it does not maintain the cervical curvature, prevent instability and osteophyte formation, and it does not preserve the vertebral disc height. Consequently, intervertebral fusion is widely recommended [24]. Initially, the iliac was often used as a substrate to achieve bone fusion. However, it may bring a considerable risk of donor site morbidity in the cervical anterior fusion technique $[25,26]$. To prevent these adverse events, many kinds of bone graft substitutes and cages have been investigated.

The stand-alone technique in anterior cervical interbody fusion is done by cage insertion without any additional support. It is a widely accepted and a proven method because not only can stand-alone cage insertion help restore foraminal height, it also provides immediate load-bearing support to the anterior column and facilitates arthrodesis [27, 28]. However, there is still considerable controversy about the stand-alone cage technique because of complications such as anterior cage migration, lower immediate stability with the cage, segmental kyphosis, and cage subsidence [6, 7].

Maintenance of the cervical curvature and disc height, prevention of cage subsidence, and conferring greater stability to the operated segment are often mentioned as reasons for the implantation of an anterior plating system. In addition, it can prevent the development of kyphosis and increase the rate of bone fusion [10, 29, 30]. Thus, the fusion procedure with a cage and a plate seems to be the golden standard in the treatment of patients with symptomatic cervical spondylosis. Nevertheless, plate migration, acceleration of disease of the adjacent segment, and dysphagia are the most frequently mentioned drawbacks associated with the anterior cage and plate technique [31, 32].

The intervertebral fusion device named Zero- $\mathrm{P}$ is a new kind of cervical fusion system that can be independently applied to single-segment or a multi-segment anterior cervical spondylosis [8]. This device has the benefits of both the cage and the anterior plate. A Zero$P$ fusion implant in the intervertebral space after decompression will not be prominent in the vertebral column. Owing to its design, Zero-P can significantly limit the potential risks of postoperative dysphagia and degeneration of adjacent segments after the internal fixation in anterior cervical fusion surgery. Furthermore, and in particular, it can increase the immediate stability of the treated segments [33].

The results of present review shows strong statistical evidence for the clinical efficacy of the two anterior cage systems in the treatment of symptomatic cervical spondylosis. It is important to emphasize that the quality of the evidence is relatively low due to the lack of randomized clinical trials (RCTs); moreover, the included observational studies may have selection bias and most studies had a small sample size, leading to a lack of statistical power [34].

In this review, it studied the relevant clinical outcomes, assessed the clinical outcome, and surgically related complications. This study confirms that the data are comprehensive enough to explore the clinical difference.

Postoperative dysphagia and its related complications are common after anterior cervical surgery. Its incidence rate reported in the literature varies from 1 to $70 \%$ [3543]. The associated significant findings indicate that the risk factors for postoperative dysphagia include the age of patients, characteristics of internal fixation and many others [44-47]. Studies have shown that the thickness of the anterior plate used in anterior cervical discectomy and fusion surgery is positively correlated to the incidence rate of postoperative dysphagia and its complications [33]. Therefore, reducing the thickness of the anterior plate could considerably reduce the rate of the

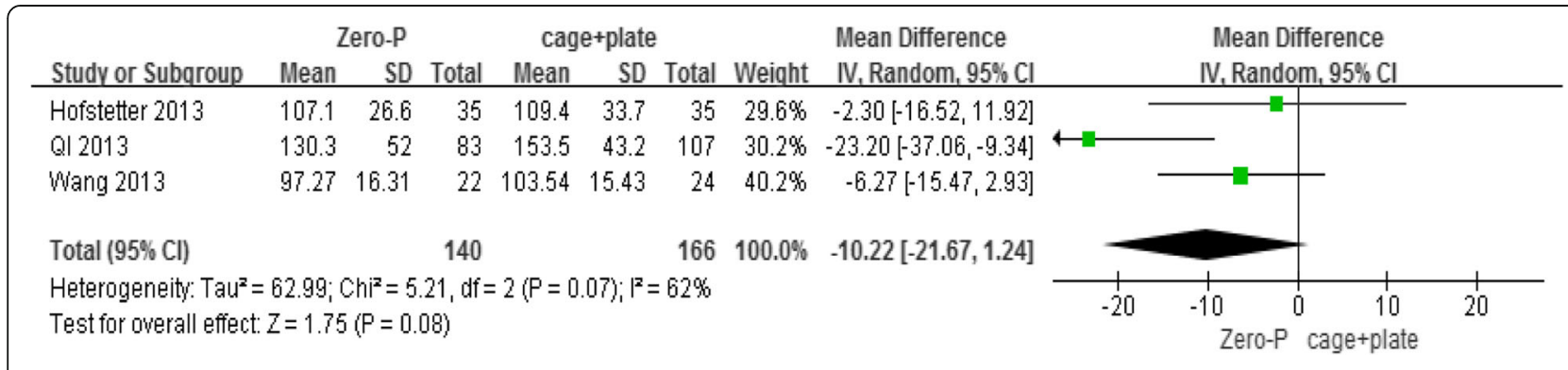

Fig. 2 Zero-P versus cage + plate on intraoperative time 


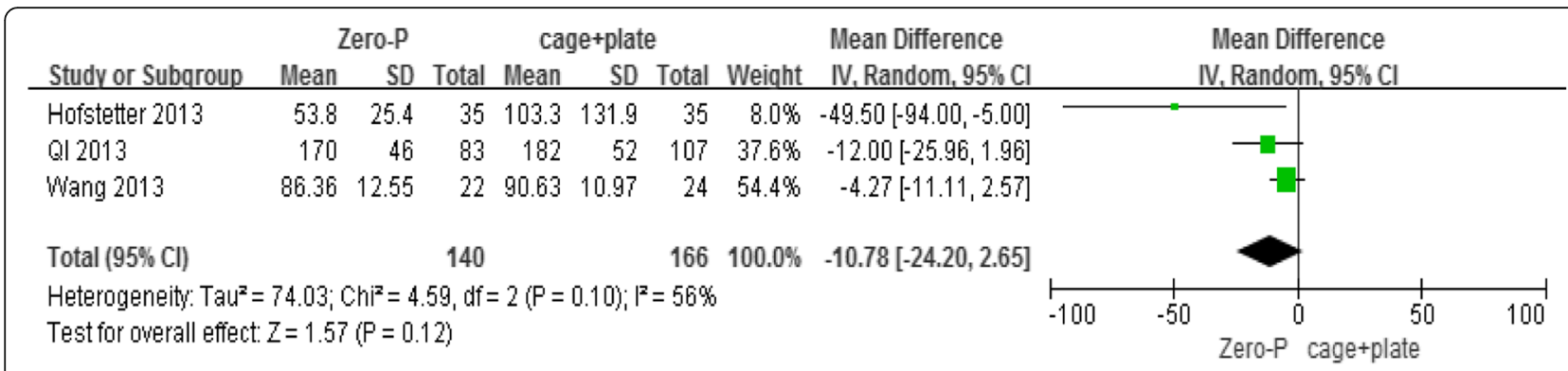

Fig. 3 Zero-P versus cage + plate on intraoperative blood loss

incidence of postoperative dysphagia and its complications. The study verified in this review shows that the incidence rate of postoperative dysphagia in the Zero-P group was significantly lower than that in the cage + plate group during first 3 months of postoperative follow-up and at the last follow-up. This might be because the design of Zero-P allowed avoiding the stimulus production of the anterior cervical plate to the esophagus and surrounding soft tissues.

Studies have shown that the Zero-P implant could demonstrate similar biomechanical properties as the traditional anterior cervical cage and plate, such as allowing good activity and stability of the surgical segments [48]. The group of Scholz et al. also selected 38 patients with cervical spondylosis who underwent Zero$\mathrm{P}$ cervical interbody fusion surgery for an average of 8 months follow-up. The follow-up results showed that all patients obtained satisfactory bone fusion and functional recovery [49]. In this review, the results suggest that the new Zero-P internal fixation system could lead to a good fusion rate similar to that with the traditional cervical fusion surgery with a cage and anterior plate. For intraoperative time and intraoperative blood loss, it was difficult to conclude which is the better technique in terms of operation trauma. Various ages of patients, degree of degeneration or skills of surgical team may be the reasons for heterogeneity in intraoperative time and blood loss.

Degeneration of adjacent segments is another common complication in anterior cervical fusion surgery, especially in multilevel procedures and with the use of an oversized plate. The result show that there was no statistical difference between the two surgical procedures. However, further analysis was not possible because of the inability to perform data merging. In addition, the long-term effects of adjacent segment degeneration are unknown for the two procedures.

In this review, satisfactory fusion was achieved by both forms of surgical treatment, with no significant difference between the two groups. Thus, Zero-P produces as good a rate of fusion and biomechanical stability as does a plate and cage construct, and both procedures corrected cervical kyphosis and improved cervical alignment.

However, Zero-P also has some disadvantages. For example, the lower screws of $\mathrm{C} 3 / 4$ and the upper screws of the $\mathrm{C6} / 7$ implant are relatively difficult to insert at an optimal angle, even if the patient does not have a short muscular neck. The increased retraction and a need for a wider skin incision also need to be considered [20].

Furthermore, many relevant issues remain unresolved: for example, whether the difference in the incidence rates of postoperative complications between the two groups are related to the surgical segments, the amount of bleeding, or other factors; whether sinking of the cage will occur; the long-term stability of the treated segment; and whether kyphosis and other complications will occur. These issues are expected to be explored and analyzed in future clinical studies.

This study has several notable strengths. First, this study confirm that this review is the first to compare the clinical effects between the new Zero-P implant with the

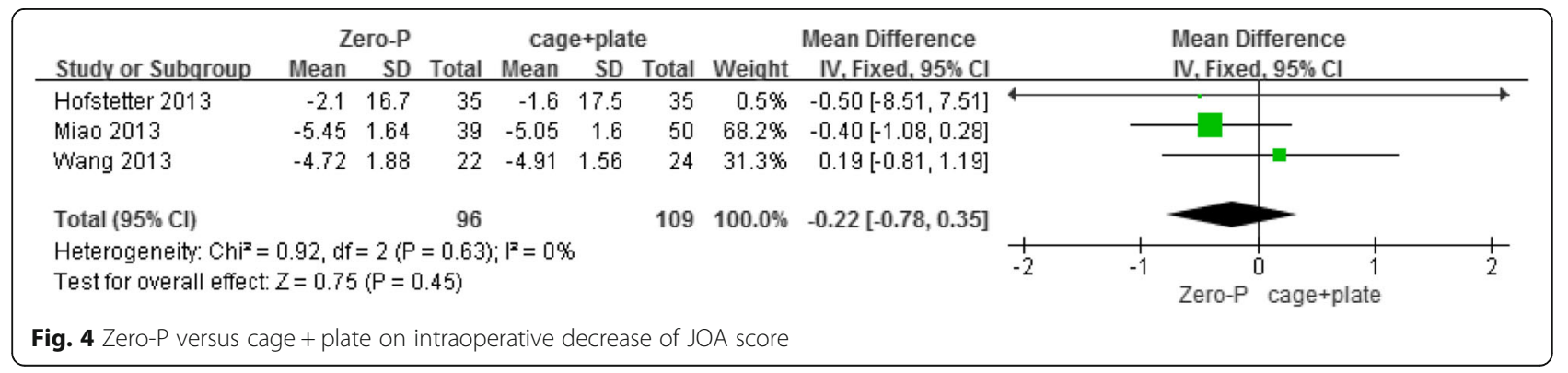




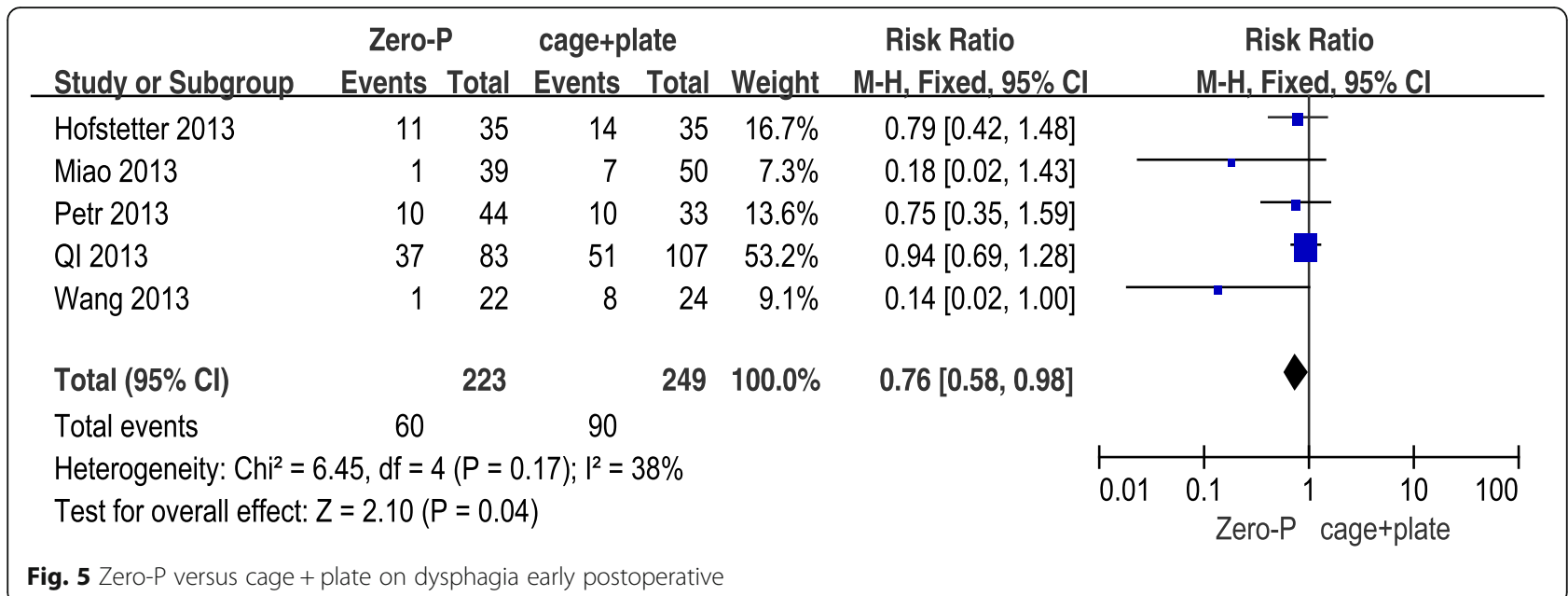

traditional anterior cage and plate in the treatment of symptomatic cervical spondylosis. Second, this study aimed to investigate the difference of the clinical effects of the two cervical anterior fusion surgeries, and judged whether the difference is clinically important. With this objective, this study conducted a systematic literature search to guarantee the comprehensiveness of the included trials. The research group believe that this is the most comprehensive and largest review thus far considering clinical outcome and surgically related complications. The included trials studied a large number of patients, and this review has adequate statistical power to analyze and explore the difference in clinical effects, despite the exclusion of numerous clinical trials because of having a low level of evidence (no control group).

However, results also have some limitations. First, this review only included five clinical trials with a relatively small sample size. Moreover, the five trials included were observational comparative studies but only one study was prospective. The prospective clinical trial did not undergo the appropriate randomization and allocation concealment. Therefore, in future clinical work, high-quality, large-sample, and multi-centered randomized and controlled clinical trials should be conducted as far as possible to provide doctors with the best evidence-based information for the treatment of cervical spondylosis. To improve the trial design quality and the level of performance, future trials should follow the guidelines for reporting clinical trials such as the CONSORT statement $[50,51]$. In addition, the follow-up period of all the included trials were relatively short, with the longest being 2 years; thus, the long-term clinical effect remains unknown. In addition, relevant related information about adjacent segment degeneration was unreported. Therefore, our research failed to draw a conclusion about these issues.

\section{Conclusions}

Both the new Zero-P interbody fusion and the traditional anterior cage and plate construct can attain good

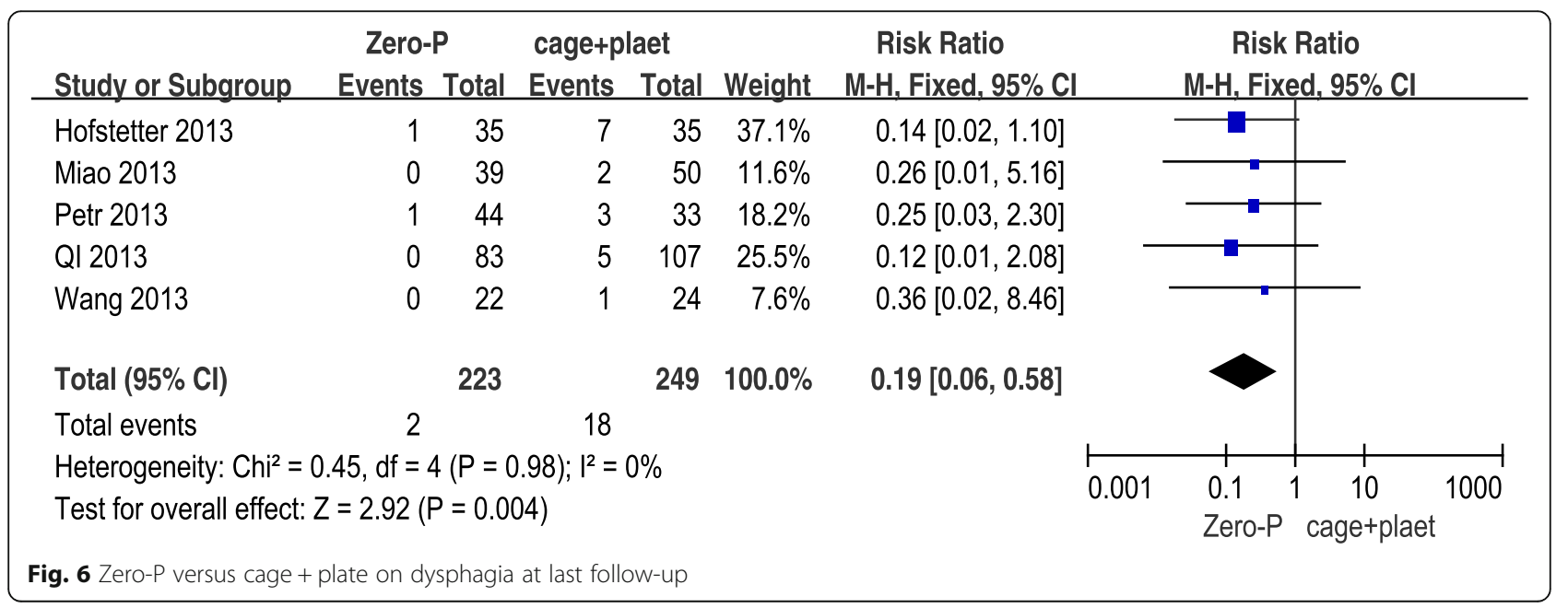


clinical efficacy and satisfactory fusion rate in the treatment of symptomatic cervical spondylosis. Zero-P can effectively reduce the risk of postoperative dysphagia and its complications, while demonstrating good clinical efficacy. However, owing to the lack of long-term followup, its long-term efficacy remains unknown. Large sample sizes and high-quality multicenter clinical trials are needed for a deeper analysis of Zero-P interbody fusion.

\section{Abbreviations}

c + p: cage and plate group; N: Number of patient; P: Prospective study; R: Retrospective study; Z: Zero-P group;

\section{Acknowledgements}

None.

\section{Funding}

The authors declare that they have not received any funding support. No funds were received in support of this work. No benefits in any form have been or will be received from a commercial party related directly or indirectly to the subject of this manuscript.

\section{Availability of data and materials}

All supporting data can be provided upon request to the authors.

\section{Authors' contributions}

MC Yin designed the study. QH designed search strategy. JM Ma designed the inclusion criteria. JY designed the types of outcomes. NC designed the radiographic outcome. ZX Yu designed the clinical outcome. YX collected the data. Cl Zhao did the date analysis. QX Shen writed the manuscript. WM revised the manuscript. Jr Xiao decided to submit the manuscript for publication. All authors read and approved the final manuscript.

\section{Competing interests}

The authors declare that they have no competing interests. We have not received any reimbursements, fees, funding, stocks, shares or salary from an organization that may in any way gain or lose financially from the publication of this manuscript, either at present or in the future.

\section{Consent for publication}

Not applicable.

\section{Ethics approval and consent to participate} Not applicable.

Received: 4 August 2015 Accepted: 29 September 2016

Published online: 18 October 2016

\section{References}

1. Tracy JA, Bartleson JD. Cervical spondylotic myelopathy. Neurologist. 2010; 16(3):176-87.

2. Vanek P, Bradac O, DeLacy P, Saur K, Belsan T, Benes V. Comparison of 3 fusion techniques in the treatment of the degenerative cervical spine disease. Is stand-alone autograft really the "gold standard?": prospective study with 2-year follow-up. Spine (Phila Pa 1976). 2012;37(19):1645-51.

3. Korinth MC. Treatment of cervical degenerative disc disease-current status and trends. Zentralbl Neurochir. 2008:69(3):113-24.

4. Le H, Thongtrangan I, Kim DH. Historical review of cervical arthroplasty. Neurosurg Focus. 2004;17(3):E1.

5. Matz PG, Ryken TC, Groff MW, et al. Techniques for anterior cervical decompression for radiculopathy. J Neurosurg Spine. 2009;11(2):183-97.

6. Gercek E, Arlet V, Delisle J, Marchesi D. Subsidence of stand-alone cervical cages in anterior interbody fusion: warning. Eur Spine J. 2003;12(5):513-6.

7. Schmieder K, Wolzik-Grossmann M, Pechlivanis I, Engelhardt M, Scholz M, Harders A. Subsidence of the wing titanium cage after anterior cervical interbody fusion: 2-year follow-up study. J Neurosurg Spine. 2006;4(6):447-53.
8. Barsa P, Suchomel P. Factors affecting sagittal malalignment due to cage subsidence in standalone cage assisted anterior cervical fusion. Eur Spine J. 2007;16(9):1395-400

9. Fraser JF, Hartl R. Anterior approaches to fusion of the cervical spine: a metaanalysis of fusion rates. J Neurosurg Spine. 2007;6(4):298-303.

10. Mobbs RJ, Rao P. Chandran NK. Anterior cervical discectomy and fusion: analysis of surgical outcome with and without plating. J Clin Neurosci. 2007;14(7):639-42.

11. Yue WM, Brodner W, Highland TR. Persistent swallowing and voice problems after anterior cervical discectomy and fusion with allograft and plating: a 5- to 11-year follow-up study. Eur Spine J. 2005;14(7):677-82

12. Fountas KN, Kapsalaki EZ, Nikolakakos LG, et al. Anterior cervical discectomy and fusion associated complications. Spine (Phila Pa 1976). 2007:32(21):2310-7.

13. Moher D, Liberati A, Tetzlaff J, Altman DG. Preferred reporting items for systematic reviews and meta-analyses: the PRISMA statement. PLoS Med. 2009;6(7):e1000097.

14. Taggart DP, D'Amico R, Altman DG. Effect of arterial revascularisation on survival: a systematic review of studies comparing bilateral and single internal mammary arteries. Lancet. 2001:358(9285):870-5.

15. Wells G, Shea B, O'Connell D, et al. New Castle-Ottawa Quality Assessment Scale-Cohort Studies. 2010. http://www.ohri.ca/programs/ clinical_epidemiology/oxford.asp.

16. Athanasiou T, Al-Ruzzeh S, Kumar $\mathrm{P}$, et al. Off-pump myocardial revascularization is associated with less incidence of stroke in elderly patients. Ann Thorac Surg. 2004;77(2):745-53.

17. Hofstetter CP, Kesavabhotla K, Boockvar JA. Zero-profile Anchored Spacer Reduces Rate of Dysphagia Compared With ACDF With Anterior Plating. J Spinal Disord Tech. 2015;28(5):E284-90.

18. Miao J, Shen Y, Kuang Y, et al. Early follow-up outcomes of a new zeroprofile implant used in anterior cervical discectomy and fusion. J Spinal Disord Tech. 2013;26(5):E193-7.

19. Vanek P, Bradac O, Delacy P, Lacman J, Benes V. Anterior interbody fusion of the cervical spine with Zero-P spacer: prospective comparative study-clinical and radiological results at a minimum 2 years after surgery. Spine (Phila $\mathrm{Pa}$ 1976). 2013;38(13):E792-7.

20. Qi M, Chen H, Liu Y, Zhang Y, Liang L, Yuan W. The use of a zero-profile device compared with an anterior plate and cage in the treatment of patients with symptomatic cervical spondylosis: A preliminary clinical investigation. Bone Joint J. 2013;95-B(4):543-7.

21. Wang ZZR, Yang $H$, et al. Clinical effects of Zero-p vs traditional titanium plate for anterior cervical discectomy and fusion. Chin J Spine Spinal Cord. 2013;23(5):440-4.

22. Liu $Y$, Hou $Y$, Yang $L$, et al. Comparison of 3 reconstructive techniques in the surgical management of multilevel cervical spondylotic myelopathy. Spine (Phila Pa 1976). 2012;37(23):E1450-8.

23. Dan NG. A prospective randomized study of anterior single-level cervical disc operations with long-term follow-up: surgical fusion is unnecessary. Neurosurgery. 1999:44(4):919.

24. Barlocher CB, Barth A, Krauss JK, Binggeli R, Seiler RW. Comparative evaluation of microdiscectomy only, autograft fusion, polymethylmethacrylate interposition, and threaded titanium cage fusion for treatment of single-level cervical disc disease: a prospective randomized study in 125 patients. Neurosurg Focus. 2002;12(1):E4.

25. Zhou J, Xia Q, Dong J, et al. Comparison of stand-alone polyetheretherketone cages and iliac crest autografts for the treatment of cervical degenerative disc diseases. Acta Neurochir (Wien). 2011;153(1):115-22.

26. Silber JS, Anderson DG, Daffner SD, et al. Donor site morbidity after anterior iliac crest bone harvest for single-level anterior cervical discectomy and fusion. Spine (Phila Pa 1976). 2003;28(2):134-9.

27. Celik SE, Kara A, Celik S. A comparison of changes over time in cervical foraminal height after tricortical iliac graft or polyetheretherketone cage placement following anterior discectomy. J Neurosurg Spine. 2007:6(1):10-6.

28. Meier U, Kemmesies D. Experiences with six different intervertebra disc spacers for spondylodesis of the cervical spine. Orthopade. 2004 33(11):1290-9.

29. Song KJ, Taghavi CE, Hsu MS, Lee KB, Kim GH, Song JH. Plate augmentation in anterior cervical discectomy and fusion with cage for degenerative cervical spinal disorders. Eur Spine J. 2010:19(10):1677-83.

30. Wang JC, McDonough PW, Kanim LE, Endow KK, Delamarter RB. Increased fusion rates with cervical plating for three-level anterior cervical discectomy and fusion. Spine (Phila Pa 1976). 2001;26(6):643-6. discussion 646-647. 
31. Lowery GL, McDonough RF. The significance of hardware failure in anterior cervical plate fixation. Patients with 2- to 7-year follow-up. Spine (Phila Pa 1976). 1998;23(2):181-6. discussion 186-187.

32. McAfee PC, Cappuccino A, Cunningham BW, et al. Lower incidence of dysphagia with cervical arthroplasty compared with ACDF in a prospective randomized clinical trial. J Spinal Disord Tech. 2010;23(1):1-8.

33. Lee MJ, Bazaz R, Furey CG, Yoo J. Influence of anterior cervical plate design on Dysphagia: a 2-year prospective longitudinal follow-up study. I Spinal Disord Tech. 2005;18(5):406-9.

34. P Oprel P, Tuinebreijer WE, Patka P, den Hartog D. Combined anteriorposterior surgery versus posterior surgery for thoracolumbar burst fractures: a systematic review of the literature. Open Orthop J. 2010;4:93-100.

35. Bose B. Anterior cervical fusion using Caspar plating: analysis of results and review of the literature. Surg Neurol. 1998;49(1):25-31.

36. Martin RE, Neary MA, Diamant NE. Dysphagia following anterior cervical spine surgery. Dysphagia. 1997;12(1):2-8. discussion 9-10.

37. Bazaz R, Lee MJ, Yoo JU. Incidence of dysphagia after anterior cervical spine surgery: a prospective study. Spine (Phila Pa 1976). 2002;27(22):2453-8.

38. Smith-Hammond CA, New KC, Pietrobon R, Curtis DJ, Scharver CH, Turner DA. Prospective analysis of incidence and risk factors of dysphagia in spine surgery patients: comparison of anterior cervical, posterior cervical, and lumbar procedures. Spine (Phila Pa 1976). 2004:29(13):1441-6.

39. Spanu G, Marchionni M, Adinolfi D, Knerich R. Complications following anterior cervical spine surgery for disc diseases: an analysis of ten years experience. Chir Organi Mov. 2005;90(3):229-40.

40. Stewart M, Johnston RA, Stewart I, Wilson JA. Swallowing performance following anterior cervical spine surgery. Br J Neurosurg. 1995;9(5):605-9.

41. Winslow CP, Winslow TJ, Wax MK. Dysphonia and dysphagia following the anterior approach to the cervical spine. Arch Otolaryngol Head Neck Surg. 2001;127(1):51-5.

42. Ratnaraj J, Todorov A, McHugh T, Cheng MA, Lauryssen C. Effects of decreasing endotracheal tube cuff pressures during neck retraction for anterior cervical spine surgery. J Neurosurg Sep. 2002;97(2 Suppl):176-9.

43. Mendoza-Lattes S, Clifford K, Bartelt R, Stewart J, Clark CR, Boezaart AP. Dysphagia following anterior cervical arthrodesis is associated with continuous, strong retraction of the esophagus. J Bone Joint Surg Am. 2008:90(2):256-63.

44. Smucker JD, Rhee JM, Singh K, Yoon ST, Heller JG. Increased swelling complications associated with off-label usage of rhBMP-2 in the anterior cervical spine. Spine (Phila Pa 1976). 2006;31(24):2813-9.

45. Shields LB, Raque GH, Glassman SD, et al. Adverse effects associated with high-dose recombinant human bone morphogenetic protein-2 use in anterior cervical spine fusion. Spine (Phila Pa 1976). 2006;31(5):542-7.

46. Riley 3rd LH, Skolasky RL, Albert TJ, Vaccaro AR, Heller JG. Dysphagia after anterior cervical decompression and fusion: prevalence and risk factors from a longitudinal cohort study. Spine (Phila Pa 1976). 2005;30(22):2564-9.

47. Frempong-Boadu A, Houten JK, Osborn B, et al. Swallowing and speech dysfunction in patients undergoing anterior cervical discectomy and fusion: a prospective, objective preoperative and postoperative assessment. J Spinal Disord Tech. 2002;15(5):362-8.

48. Scholz M, Reyes PM, Schleicher P, et al. A new stand-alone cervical anterior interbody fusion device: biomechanical comparison with established anterior cervical fixation devices. Spine (Phila Pa 1976). 2009;34(2):156-60.

49. Scholz M, Schnake K, Pingel A, Hoffmann R, Kandziora F. A new zero-profile implant for stand-alone anterior cervical interbody fusion. Clin Orthop Relat Res. 2011;469(3):666-73.

50. Begg C, Cho M, Eastwood S, et al. Improving the quality of reporting of randomized controlled trials. The CONSORT statement. JAMA. 1996; 276(8):637-9.

51. Schulz KF, Altman DG, Moher D. CONSORT 2010 statement: updated guidelines for reporting parallel group randomized trials. Ann Intern Med. 2010;152(11):726-32

\section{Submit your next manuscript to BioMed Central and we will help you at every step:}

- We accept pre-submission inquiries

- Our selector tool helps you to find the most relevant journal

- We provide round the clock customer support

- Convenient online submission

- Thorough peer review

- Inclusion in PubMed and all major indexing services

- Maximum visibility for your research

Submit your manuscript at www.biomedcentral.com/submit

) Biomed Central 